\section{Adapting to Climate Change: Challenges for Uji Tea Cultivation}

\author{
Fitrio Ashardiono ${ }^{a^{*}}$, Monte Cassim ${ }^{\mathrm{b}}$ \\ ${ }^{a}$ Ritsumeikan University, 2-15o Iwakura-cho, Ibaraki, Osaka \\ 567-8570, Japan \\ ${ }^{b}$ Ritsumeikan Research Center for Sustainability Science, 56-1 \\ Toji-in Kitamachi Kita-ku, Kyoto 603-8577, Japan
}

Received: January 27, 2015/ Accepted: April 24, 2015

\section{Abstract}

Rapid changes in the climatic conditions have becoming more evident with increasing degree of its intensity and extremities. Direct effects of these changes are felt by agriculture industries especially those which are utilizing terroir elements, environmental of a certain area and its human interaction such as the tea cultivation industry in Uji Area. While tea plant itself is sensitive towards changes in the microclimatic conditions, the changes have also affected terroir elements of Uji Area such as climatic and by soil factor. As the oldest and most famous green tea producing region in Japan, Uji Tea reputation have been built through its terroir characteristic and their longrunning traditional agriculture knowledge. Changes in the climatic conditions have altered bud break timing thus changed the harvest timing. Beside changes in the tea plant response, damages caused by frost, drought, heavy rain and temperature extremities have directly affected the quality and quantity of the tea production. Observation and surveys conducted in Uji showed that these changes are not only affecting cultivation process, but also indirectly leading to socio-economic issues in the tea farmer community. It is necessary to utilize cultivation process based on climate change adaptation framework that enable Uji tea farmers to pro-actively adapt with the on-going changes which will ensure the sustainability of Uji area as a tea-growing region.

Keywords: Climate Change; Uji Tea Cultivation; Terroir.

Corresponding Author

Tel.: +81-75-465-7877; Fax.: +81-75-465-7877;

E-mail: fitrio.as@gmail.com

\section{Uji Tea Cultivation}

Although Uji Tea might not be a familiar name Japanese green tea is very much popular as a high quality tea with health benefit properties among tea enthusiast. Even so what is commonly known about Japanese green tea would be matcha or sen-cha which are types of green tea, whereas information about the location of the tea growing region is not known. Uji Area is the oldest and most famous tea growing region in Japan in which according to historical archive tea cultivation in the area begins in $1191 \mathrm{AD}$ [1]. Originally Uji Tea refers to tea products which are cultivated within the borders of Uji Area, and it is well known for its extraordinary quality as it only caters to the nobility. Because of its resource consuming methods, traditionally the tea produced in Uji Area is only available in a low volume, therefore in order to comply with the continuous high demand from consumers, the Kyoto Tea Cooperative (京都府茶業組合) (2006) [2] defined Uji Tea as tea products which are grown in four prefectures: Kyoto, Nara, Shiga and Mie; but processed inside Kyoto Prefecture by a tea manufacturer which is based in Kyoto Prefecture.

\subsection{Location of Uji Area}

Uji Area or Uji City is situated in the south part of Kyoto Prefecture with a land area of $67.55 \mathrm{~km} 2$. Although this area is famous for tea cultivation, currently there are only 113 active tea farmers inside Uji Area from the total population of 189,6o9 residents [3]. Uji Area topographical situation consist of river plains and flat lands with hills on the east and south part of the area. Tea plantations are mostly located around river plains and on the hills area, whereas each location produced different characteristic of tea products thus terroir conditions of each location directly affect the tea characteristics.

\subsection{Terroir of Uji Tea}

Important Terroir factors in a tea cultivation area consist of the natural environmental factors which are: 1) Climate; 2 ) Soil; 3) Topography; and 4) Cultivars [4][5]. For generations tea farmers in Uji Area have been carefully utilizing these natural characteristics in the production of Uji Tea which became the basis for the current terroir system which formed through the combination of traditional agriculture practices with natural environmental factors. As mentioned previously, Uji tea farmers understand that different location of tea plantation resulted in different characteristic of tea products. These characteristics emerges by taking advantages of the soil type differences, topographical conditions and combined with thorough selection of the planted cultivars. 
Currently there are 81.6 Ha of tea plantations in total whereas actively producing tea plantation is 8o Ha [1], which is comparatively small compared to other tea producing regions in Japan. In general tea farmers in Uji Area are cultivating eleven tea cultivars, which are: 1) Uji Midori; 2) Kyo Midori; 3) Yabukita; 4) Samidori; 5) Asahi; 6) UjiHikari; 7) Ogura Midori; 8) Gokou; 9) Komakage; 10) Oku Midori; and 11) Sae Midori [4]. Among these eleven cultivars seven cultivars: Uji Midori, Kyo Midori, Samidori, Asahi, UjiHikari, Ogura Midori, Oku Midori and Sae Midori are tea cultivars which are developed from tea plants native to the region.

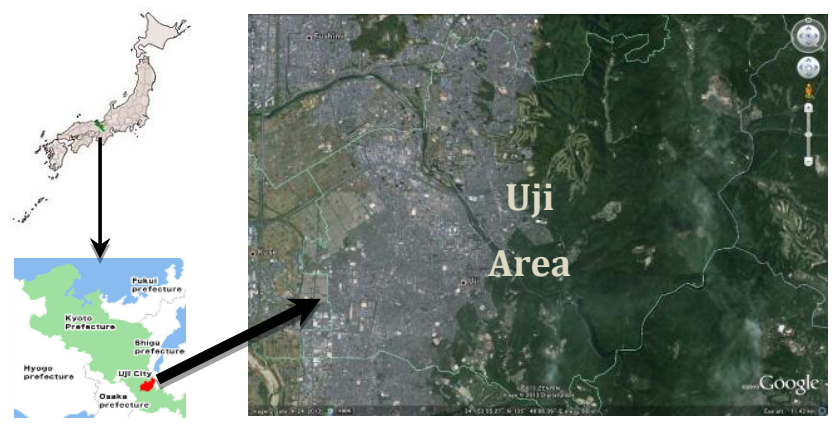

Figure 1 Location of Uji Area [1]

(Source: Kyoto Prefecture Government, 2014; Google Maps, 2014)

\subsection{Traditional Tea Cultivation}

For generations tea farmers in Uji Area retain traditional cultivation methods which relies heavily on manual labor for cultivation processes, as well as manual leaf plucking during the tea harvest. One of the unique cultivation methods utilized by the tea farmers in Uji Area is the use of traditional covering methods during tea cultivation process, thus knowledge of this practice are passed down through generations of tea farmers. This method is especially essential to produce high quality matcha and gyokuro. In this unique method, tea bushes are covered with sunlight blocking materials at the moment of first bud break for approximately three to four weeks. In the first two to three weeks the light intensity is reduced by 95 percent and in the last week prior to harvest the light intensity is further reduced to 98 percent. With reduced sunlight condition, tea plants would produce more chlorophyll in the tea leaves thus increased amino acid and reduced catechin level, whereas it is believe to give more taste and sweetness to the tea products.

Based on surveys and observations, it is revealed that each tea farmers have their own methods and system in achieving reductions in light intensity. The observed variation includes: 1) selection of covering material; 2) layering methods and installation height; 3) duration of covering period. Covering materials used in this method are traditionally using woven reeds and straws, although other artificial material like black vinyl sheet is also used. This method contributes directly to the characters of Uji Tea flavor and taste. Because of this complex and resource consuming cultivation method, tea harvest in Uji Area can only be conducted once a year.

a)
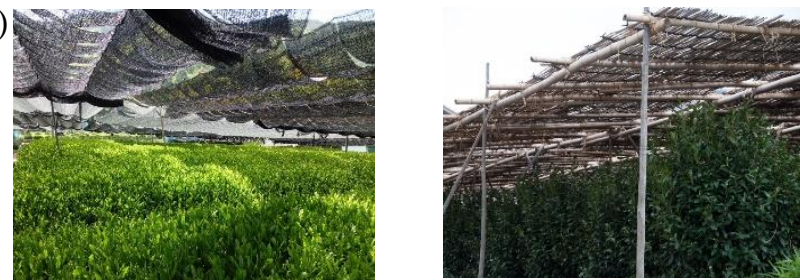

c)

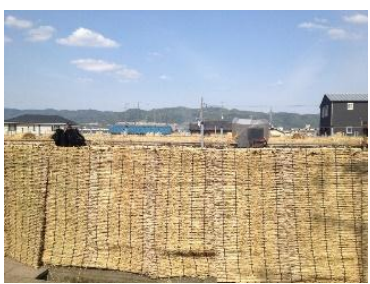

d)

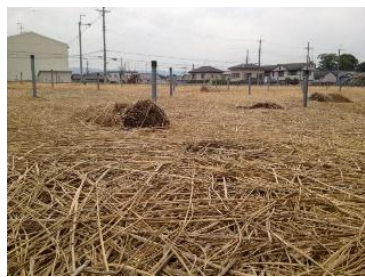

e)
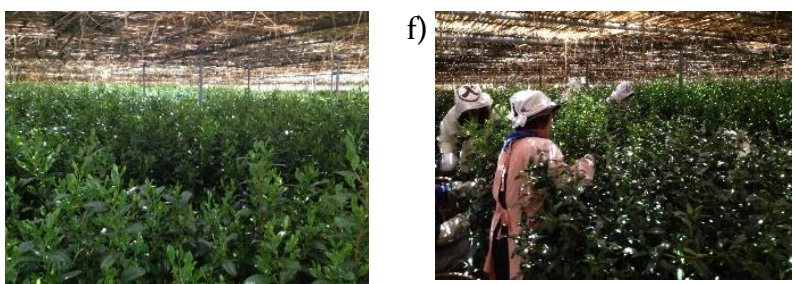

Figure 2 (a) Covering method using black vinyl sheet; (b) (c) (d) traditional covering method using woven reeds and straws; (e) tea bushes under covering method; (f) manual tea harvesting (Source: Author, 2014)

\section{Social Surveys and Observations}

As a method to further understand the climate change effect towards Uji Tea cultivation, social surveys and observations are conducted on several tea farmers and their tea plantations between late 2013 to early 2014. Currently as there are 113 active tea farmers in Uji Area, whereas this number is actually different than what it represent. In each tea farmer's household, at least two to three individual are registered as tea farmer, thus this means the actual number of active tea plantations are only half or one third of the registered number. Through preliminary research, there are 15 tea farmers which cooperated in the social surveys and observations. Although the number is small, each respondent is most likely representing at least two tea farmers from their household, therefore the actual number of respondents would be more than 30 farmers.

Interviews are conducted using semi structure method, in which there were seven main guiding questions. The questions are structured into: 1) Demographic Information; 2) Agriculture Knowledge; 3) Terroir Comprehension; 4) 
Opinion on Climate Change; 5) Seasonal Cultivation Process; 6) Utilization of Precision Agriculture; and 7) Socio-Economic and Environmental Issues. From the total 15 tea farmers, age group of the interviewed farmers consist of 4 farmers in the age group 30-39 years; 9 farmers in the age group 40-49 years; 1 farmers in the age group 50-59 years; and 1 farmers in the age group 6o-69 years. Among them 78 percent has been cultivating tea for more than 20 years, while 22 percent in between 15 to 20 years of experience. This number correlates with the questions about terroir comprehension, whereas 77 percent of the respondents received knowledge on tea cultivation from their family, while the remaining 23 percent acquired cultivation knowledge through self-experience as well as information from fellow tea farmers. From this data it can be concluded that there are evidence of traditional agriculture knowledge transfer among generations in the tea farmer's community of Uji Area.

\section{Changing Climatic Behavior}

The on-going changes in the climatic conditions of Uji Area have clearly shown that there are increasing trends of extreme weather events [4][5][6]. These events undoubtedly have affected the tea cultivation process cycle, whereas tea plants are sensitive towards changes in the microclimate condition especially from temperature fluctuations. As explained previously, in order to attain the renowned characteristic of Uji Tea, young tea leaves need to be plucked before it started to harden, whereas exposure to extreme climatic events will accelerate the hardening process.

In the past years, the observed changes in Uji Area are: 1) sudden drop in temperature during spring season; 2) higher temperature during fall season; 3) changes in quantity and period of rainy season; 4) longer period of drought; 5) diminishing morning fog; 6) diminishing characteristic of high quality tea. Social surveys which are conducted inside Uji Area tea farmer's community revealed that the extreme climatic events have becoming more frequent over the past ten years. In this survey from 15 tea farmers' respondents, it can be seen the percentage how climate change are effecting the cultivation processes. 36 percent of the effect caused by temperature fluctuations, 32 percent is drought, 18 percent is because of frost event and 14 percent is caused by excessive rainfall.

\subsection{Low Temperature and Frost Events}

Based on regression analysis between tea productivity and average temperature between 2002 to 2013, the result showed that crucial period in the tea cultivation process occurred between late February until the beginning of May [5][6]. Any major climatic events that happened during this period would seriously affect the quality and quantity of the harvest. Low and sudden temperature drop will hinder the growth of leaf bud because tea plant is only active on temperature condition above $10^{\circ} \mathrm{C}$, thus any occurring frost events will permanently damage the leaf buds effectively reducing the harvest yield.

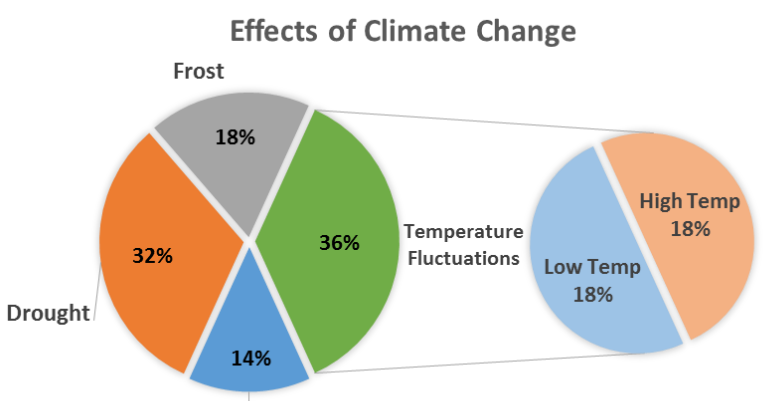

Figure 3 Effectsegfeslimate Change on Tea Cultivation in Uji Area Rainfall $\quad(n=15)$

\subsection{Excessive Rainfall}

Post harvesting season, records have shown that excessive rainfall were happening in Uji Area, in which excess water rapidly overflowed the tea plantations which are located along river plains or those which are located in low lands. This temporary flooding washed away important nutrients from the soil, whereas if the flooding is not quickly drained the excessive amount of water will damages the tea plant.

\subsection{Drought and High Temperature}

On the opposite side during summer season prolonged drought directly affected the plant growth and reduce the quality and quantity of next season harvest, as tea plant will not be in a healthy condition. In general Uji Area tea farmers do not water the tea plantation, but as the drought period have becoming longer in addition with increasing occurrences of days with high temperature, they are forced to start watering the tea plantation or risk having a poor harvest in the next season.

Warm temperature during fall season have also become an issue whereas instead dropping slowly, the temperature would suddenly drop at the end of the season, causing abrupt stop on the tea plant growth which have a negative impacts to the plant, thus this will also reduce the quality of next season harvest.

\section{Socio-Economic Issues}

Although changes in the microclimatic conditions in Uji Area do not have any immediate disastrous effects toward tea plants, it has significantly reduced the quality and quantity of the tea harvest. Under these conditions in the near future Uji Area tea farmers might not able to produce tea products which retain the well-known quality and characteristic of Uji Tea. For generations Uji Area has become famous as a tea growing region in Japan thus tea products from this area are later known as Uji Tea, 
especially matcha product from Uji Area is known as the benchmark for highest quality matcha in Japan.

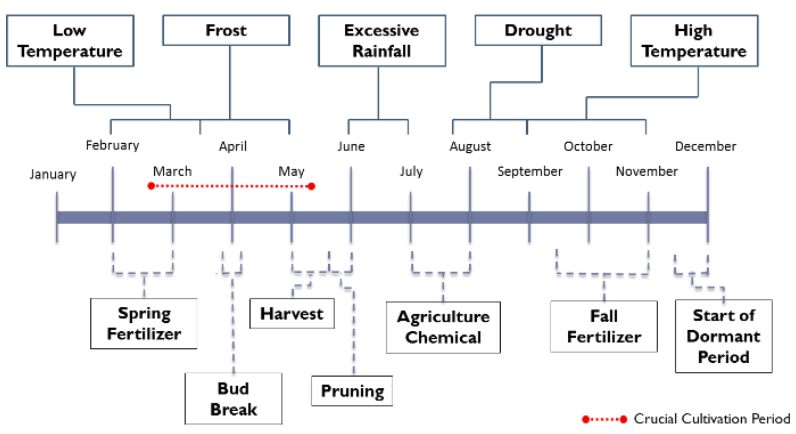

Figure 4 Climate Change Effects on Seasonal Tea Cultivation Process in Uji Area

\subsection{Economic Issues}

Despite having a well-known status, tea farmers in the Area are actually facing several other issues apart from the issues in the cultivation process. Currently the main issues that are faced by the tea farmers are mostly from economic perspectives, whereas declining sales value and increasing expenses in cultivation have slowly affecting tea farmer's financial condition. Showed in figure 5 that combination of both issues contribute 84 percent to the main issues currently faced by the farmers

Facing these financial issues most tea farmers expressed that, is has been increasingly difficult to support the financial condition of their household only with tea cultivation. As seen in figure 6 apart from the 77 percent that expressed apparent pressures in their financial condition there were more daunting answers, where as many as 23 percent mentioned that it is not possible to support their household only with tea cultivation, therefore beside tea cultivation these farmers also produce and distribute their own tea products. Despite knowing the latent danger of climate change effects not all of the farmers were interested in investing their resources to countermeasure climate change effects due to financial constraints.

\subsection{Social Issues}

Gradually the current existing economic issues will be further worsened by climate changes effects, creating many uncertainties in the future of tea cultivation industry. This condition has made the younger generation becoming less interested in continuing their family business. Faced with the existing economic uncertainties, young tea farmer needs to understand intricate and complex traditional cultivation process in the tea cultivation. These requirements further increase the challenges in entering the industry, thus evidently securing a successor in the tea cultivation business becoming an issue in Uji Area. Although at the moment this issue has yet to dominate, as the population ages this will become a serious issue which will affect the sustainability of the area as a prominent tea growing region.

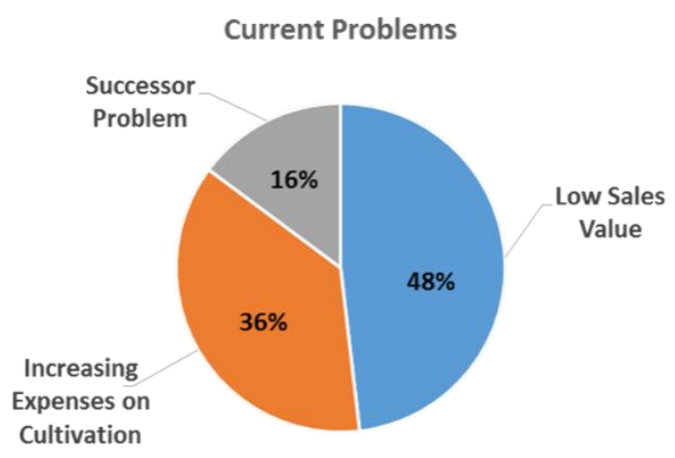

Figure ${ }_{5}$ Current Problems Faced by Tea Farmers in Uji Area

\section{Current Economic Condition}

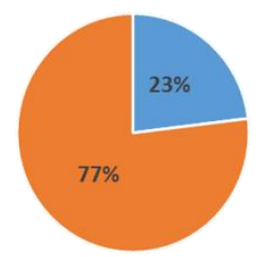

- Not possible to support only with tea cultivation

= Becoming more difficult

Figure 6 Current Economic Conditions of Tea Farmers in Uji Area

If these issues are not properly addressed, it would not be long until teas produced in Uji Area would disappear, whereas this will also means the social structure of tea farmer's community in Uji Area has collapsed. Although protecting Uji Area as a tea growing region is important, much more crucial issues would need to be placed on preserving traditional cultivation knowledge which have been passed down for generations.

\section{Conclusion and Further Discussions}

Based on social survey result and observations, although the tea farmers understand the possible threat due to climate change effects, not all of the tea farmers are fully concern nor are able to dedicate their resources to immediately counteract with the on-going changes. However, in general they understand the latent danger if immediate action are not taken to adapt with the rapid changes. The social survey have revealed that tea farmers in Uji Area are more concerned with their current economic conditions as well as with the current social situations in Uji Area. As mentioned in the previous research, seen in figure 7 [4][5], in order to swiftly adapt with the on-going climate change, and to 
maintain the economic and environmental sustainability of a climate change affected tea cultivation region, utilization of precision agriculture system is necessary as a tool to swiftly understand the changes as well as the basis for creating new agriculture methods [4].

Current analysis in the situation of Uji Area showed that utilization of precision agriculture system as a climate change countermeasure method might further burden the economic condition of the tea farmers to some extent, which already under pressure. Nonetheless by utilizing agro-informatics system, tea farmers would be able to receive many benefits such as obtaining detail monitoring and measurement data of their tea plantation conditions which is crucial for deciding optimal timing and types of cultivation intervention during the growth period. Collected data will also become very useful for generating traceability documents of their products. Through utilization of traceability system Uji Area tea farmers would be able to expand their products market not just domestically but internationally as it provides all of the necessary information about the products origin and its production process which will become their products quality assurance to the consumers.

The utilization of precision agriculture system which based on traditional agriculture knowledge will further refine the existing cultivation system, thus creating new intervention methods to ensure the quality and quantity of the tea harvest. As seen in figure 4 , tea farmers would be able to better understand the condition and conduct accurate cultivation intervention during any phase of tea cultivation process. Further use of the precision system will lead to the identification and utilization of important bioclimatic indicators such as Heliothermal Index, Cool Nights Index and THSW Index which are useful in selection of land and cultivars as well as prediction of tea harvest quantity and quality [5]. Through effective intervention based on bioclimatic indicators information from agro-informatics system, tea farmers would be able to develop new techniques and methods to maintain the high standard of tea quality or even more adding new value to the tea products.

Combined system between the concept of terroir with precision agriculture system would help young tea farmers to better understand traditional tea cultivation process which is being practiced, thus it will draw more interest from the younger generation to continue their family-run business. There is a need for the government to properly address this issue in order to preserve the long-standing agriculture tradition in Uji Area because this is an intangible heritage. Redefinition of Uji Tea meaning and scope should properly include the terroir factor which will characterize the tea products, which then appropriate categorization can be created. From this categorization the government should formulate policies that help ensure the sustainability of Uji Area as tea growing region, whereas in a bigger scope the policy framework could be applied to other heritage cultivation areas.

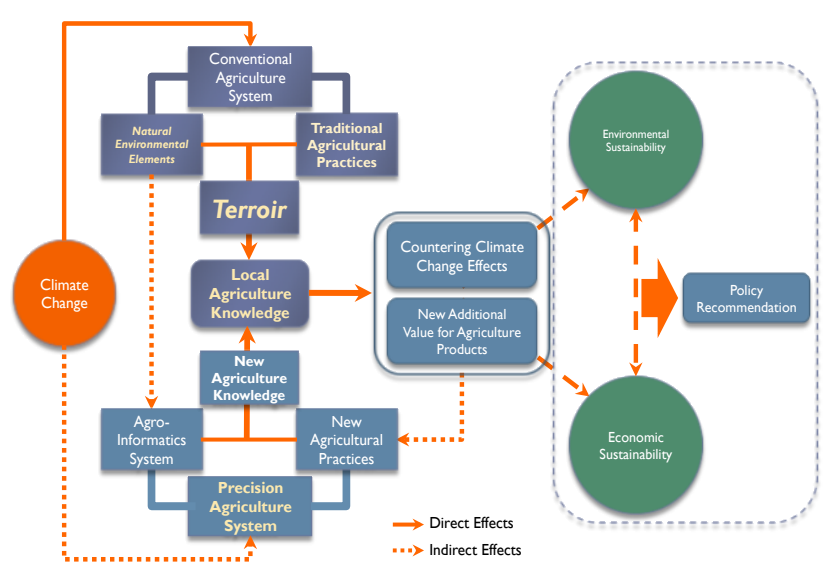

Figure ${ }_{7}$ Climate Change Adaptation Framework [4][5]

\section{References}

[1] Kyoto Prefecture Government. History of Uji Tea (Translated from Japanese). 2011.

[2] Kyoto Tea Cooperative (京都府茶業組合). Definition of Uji Tea (Translated from Japanese). 2006.

[3] Kyoto Prefecture Government. Tea Industry Statistic (Translated from Japanese). 2012.

[4] Ashardiono, F. Climate Change Adaptation for Agro-Forestry: Sustainability and Potentials in the Tea Industry. Policy Science 2014;21 (2):99-113.

[5] Ashardiono, F., Cassim, M. Climate Change Adaptation for Agro-Forestry Industries: Sustainability Challenges in Uji Tea Cultivation. Procedia Environmental Sciences 2014;20:823-831.

[6] Kyoto Prefecture Tea Industry Research Center. Annual Cultivation Growth Data (Translated from Japanese). 2013 